\title{
Erro Médico: a Perspectiva de Estudantes de Medicina e Direito
}

\section{Medical Error from the Perspective of Medical Students and Law Students}

\author{
José Antônio Chehuen Neto ${ }^{I}$ \\ Mauro Toledo Sirimarco \\ Nathália Stela Visoná de Figueiredo ${ }^{I}$ \\ Tatiane Neto Barbosa \\ Thiago Gonçalves da Silveira
}

\section{PALAVRAS-CHAVE \\ - Erros Médicos. \\ - Educação Médica. \\ - Ética Médica. \\ - Legislação Médica. \\ - Responsabilidade Legal.}

\section{RESUMO}

Nas últimas décadas, houve um crescimento das implicações em sociedade do erro médico, assunto em que se entrelaçam Medicina e Direito. Este estudo procurou conhecer a percepção de estudantes de Medicina e Direito sobre erro médico, avaliando nível de interesse e informação, e a necessidade de abordar o tema na graduação e como ela ocorre para cada área, na sua ótica. Estudo observacional descritivo transversal foi realizado na Universidade Federal de Juiz de Fora (MG) em 2008 com 185 alunos de Medicina e 119 de Direito. 88,7\% dos alunos de Medicina (MED) e 92,4\% de Direito (DIR) referiram conhecimento sobre erro médico. O interesse se dá por ser um tema muito discutido atualmente. Os alunos consideram necessária sua abordagem na graduação (97,8\% MED e 94,9\% DIR). É importante discutir um tema tão atual na graduação de Medicina e de Direito pela contribuição que pode ser oferecida para diminuir o ciclo vicioso de erros, iatrogenias e processos jurídicos, além de possibilitar uma reflexão acerca do papel da educação médica na construção ética de novos profissionais.

Recent decades have witnessed an increase in the societal implications of medical error, a subject in which Medicine and Law intertwine. This study focused on medical error from the perspective of medical students and law students, assessing their level of interest and information and the need to discuss the topic during undergraduate education and how it occurs in each field, in their view. A cross-sectional, descriptive, observational study was conducted at the Federal University in Juiz de Fora, Minas Gerais State, in 2008 with 185 medical students and 119 law students. 88.7\% of the medical students and $92.4 \%$ of the law students reported knowledge of medical error. The interest was due to the fact that medical error is currently a widely discussed issue. The students thought the issue should be addressed in their undergraduate education (97.8\% of medical students and $94.9 \%$ of law students). It is important to discuss such a current issue in undergraduate education in both medicine and law, because of the potential for decreasing the vicious circle of errors, iatrogenesis, and law suits, in addition to fostering reflection on the role of medical education in the ethical training of young professionals. 


\section{INTRODUÇÃO}

A qualidade da atividade médica é um tema de preocupação social desde a Mesopotâmia (século 18 a.C.), onde o Código de Hamurabi já estabelecia a responsabilidade jurídica do médico em caso de atuação de má qualidade - "olho por olho, dente por dente" ${ }^{11,2}$ (p. 11). Na Grécia Antiga (460-351 a.C.), Hipócrates de Cós, o pai da medicina, formulou o Princípio da Não Maleficência, Primum Non Nocere: "Aos doentes, tenha por hábito duas coisas: ajudar ou, pelo menos, não produzir dano $^{\prime 1,2,3}$ (p. 11).

Embora não seja totalmente nova a repercussão da responsabilidade médica e das demandas por eventos adversos e negligências médicas, nas últimas décadas do século 20 houve um crescimento das implicações de erro médico, principalmente pelo aumento do conhecimento público e de processos jurídicos relacionados ${ }^{4}$. Em 1999, os Estados Unidos criam a Agency for Healthcare Research and Quality para investigar a qualidade do cuidado médico e garantir a seguridade do paciente $^{5,6}$. Em 2002, a 55 a Assembleia Mundial da OMS formula a Aliança Mundial para a Seguridade Clínica do Paciente, gerando maior preocupação dos prestadores de serviços médicos com ressarcimentos financeiros por má prática e a necessidade de seguros de indenização, com a subsequente elevação dos custos de saúde - modelo de Medicina Defensiva ${ }^{4,5,7-11}$

Medicina e Direito se entrelaçam quanto ao assunto pela relevância na vida profissional do médico, como agente ativo, e na do profissional do Direito, que estuda suas implicações legais. Devido à grande mobilização em torno do tema atualmente e, mais ainda, aos apelos por conduta ética em ambas as áreas, ganha importância essa discussão na graduação, além da necessidade de se formarem profissionais mais bem informados e preparados para as incipientes necessidades que emergem na sociedade.

A terminologia mais aceitável nessa área, porém ainda pouco difundida na literatura, é erro clínico - evento adverso que pode ser cometido por qualquer profissional da área de saúde (não somente o médico), passível de ser racionalmente prevenido ${ }^{10}$. Evento adverso é um resultado clínico adverso àquele esperado e que se deve a erro de diagnóstico, tratamento ou cuidado com o paciente, ou ao curso natural da patologia, ou a condições próprias do paciente. Embora a referência aqui feita a "erro médico" devesse ser direcionada a "erro clínico", não se utilizou tal terminologia e optou-se por manter a nomenclatura mais conhecida, para facilitar o entendimento dos entrevistados. Erro médico faz parte do que se denomina iatrogenia, estando relacionado a um resultado negativo da prática médica ${ }^{12}$. A responsabilidade jurídica é do tipo culpa (ausência de intenção), com as modalidades: (a) negligência: falta de cuidado; (b) imprudência: realização de uma ação impensada ou precipitada; (c) imperícia: inabilidade, imaestria ${ }^{4,8,13}$.

O estudo realizado se propõe a conhecer a percepção de estudantes de Medicina e de Direito de uma universidade federal a respeito de erro médico, avaliando nível de interesse e de informação sobre o assunto. Procura-se perceber também como os estudantes avaliam a necessidade de abordagem do tema na graduação e como ela ocorre em cada área.

\section{MÉTODOS}

Estudo observacional descritivo transversal com abordagem quali-quantitativa realizado na Universidade Federal de Juiz de Fora (MG). A pesquisa foi aprovada pelo Comitê de Ética em Pesquisa Humana da UFJF.

De abril a junho de 2008, foram entrevistados 185 estudantes de Medicina (77,08\%) e 119 alunos de Direito diurno $(79,34 \%)$. Cada turma do curso de Medicina tem 80 alunos (total de 240 pesquisados), enquanto no Direito diurno há 50 alunos (total de 150).

Participaram da pesquisa alunos matriculados no sexto, sétimo e oitavo períodos de ambos os cursos, que aceitaram, via Termo de Consentimento Livre e Esclarecido, responder ao questionário individualmente, de forma adequada, completa e imediata, uma vez estando presentes em sala de aula durante a aplicação pelos pesquisadores.

Foram excluídos do processo estudantes de ambos os cursos do primeiro ao quinto período, por contato insuficiente com a realidade profissional e com o tema erro médico nesse momento da aprendizagem. Também foram excluídos os alunos do nono ao décimo segundo período, por dificuldade de localização, já que realizam atividades fora do ambiente acadêmico (estágios, internato e monografia para término de curso). E, ainda, aqueles que se recusaram a participar ou não devolveram os questionários logo após o término do período de aplicação.

O estudo foi dividido em duas partes. Na primeira, procurou-se perceber o domínio pelos estudantes entrevistados da temática proposta, se há coerência e boa fundamentação, além de instigar sua capacidade de formular reflexões críticas neste contexto a partir de conhecimentos prévios. Posteriormente, o instrumento utilizado possibilitou que os alunos avaliassem, sob sua ótica, a necessidade de abordagem do tema na graduação, se ocorre tal abordagem durante a graduação e, em caso afirmativo, qual o seu nível de qualidade.

$\mathrm{O}$ instrumento de coleta de dados aplicado seguiu essa linha de raciocínio, sendo composto por um questionário estruturado com 11 perguntas abertas e de múltipla escolha. Para 
cada pergunta fechada com mais de uma opção de justificativa, uma ou mais alternativas foram aceitas, sendo cada uma avaliada estatisticamente de forma independente.

Os dados referentes às questões de múltipla escolha são apresentados em porcentagens totais. Representando a fala livre dos alunos entrevistados, as respostas abertas foram parafraseadas de forma a embasarem a discussão.

\section{RESULTADOS}

Na primeira parte do estudo, o conhecimento do significado do conceito erro médico foi referido por $88,7 \%$ dos estudantes de Medicina e $92,4 \%$ dos de Direito. Para $63,8 \%$ na Medicina e $61,0 \%$ no Direito, o principal motivo de interesse é o fato de o assunto estar sendo muito abordado atualmente. Além disso, $64,3 \%$ dos acadêmicos de Medicina se interessam por ele, pois se preocupam em ter que lidar com processo jurídico por erro médico na vida profissional futuramente.

Quanto ao domínio do tema, a Tabela 1 mostra os possíveis fatores desencadeantes do aumento do número de processos jurídicos de erro médico no Brasil e no mundo na atualidade, na perspectiva dos estudantes entrevistados. Paralelamente, foram questionadas possíveis formas de enfrentamento desta questão e de prevenção da sua ocorrência, o que está representado na Tabela 2.

\section{TABELA 1}

Principais fatores que estudantes de Medicina e de Direito da UFJF consideram como desencadeantes do aumento do número de processos de erro médico na atualidade, em maio

$$
\text { de } 2008
$$

\begin{tabular}{|c|c|c|}
\hline & Medicina & Direito \\
\hline $\begin{array}{l}\text { Aumento do número de faculdades de } \\
\text { Medicina }\end{array}$ & $31,9 \%$ & $61,9 \%$ \\
\hline Influência da mídia sobre a população & $55,1 \%$ & $20,3 \%$ \\
\hline $\begin{array}{l}\text { Deterioração da relação médico- } \\
\text { paciente }\end{array}$ & $54,6 \%$ & $35,6 \%$ \\
\hline $\begin{array}{l}\text { Maior acesso à informação e } \\
\text { conhecimento de direitos pela } \\
\text { população }\end{array}$ & $54,6 \%$ & $43,2 \%$ \\
\hline Crise do sistema de saúde & $33,0 \%$ & $52,5 \%$ \\
\hline $\begin{array}{l}\text { Utilização inadequada da tecnologia, } \\
\text { sobrepondo anamnese e exame físico }\end{array}$ & $24,3 \%$ & $19,5 \%$ \\
\hline $\begin{array}{l}\text { Aumento do número de profissionais } \\
\text { de Direito sem aumento correspondente } \\
\text { no seu campo de atuação }\end{array}$ & $18,4 \%$ & $6,8 \%$ \\
\hline Outros & $2,2 \%$ & $1,7 \%$ \\
\hline
\end{tabular}

\section{TABEla 2}

Medidas para a prevenção de erro médico de acordo com estudantes de Medicina e de Direito da UFJF, em maio de 2008

\begin{tabular}{lcc}
\hline & Medicina & Direito \\
\hline $\begin{array}{l}\text { Resgate da relação médico-paciente } \\
\text { (RMP) }\end{array}$ & $79,1 \%$ & $39,0 \%$ \\
$\begin{array}{l}\text { Melhorar a qualidade da formação } \\
\text { acadêmica e incentivar a educação } \\
\text { continuada dos profissionais de }\end{array}$ & $47,8 \%$ & $72,9 \%$ \\
$\begin{array}{l}\text { Medicina } \\
\text { Efetuar mudanças no sistema de saúde }\end{array}$ & $44,0 \%$ & $51,7 \%$ \\
$\begin{array}{l}\text { Usar em conjunto história clínica, exame } \\
\text { físico e tecnologia }\end{array}$ & $46,7 \%$ & $47,5 \%$ \\
$\begin{array}{l}\text { Adotar protocolos de ação } \\
\text { Substituir a abordagem punitiva pela } \\
\text { educativa }\end{array}$ & $37,9 \%$ & $18,2 \%$ \\
\begin{tabular}{l} 
Outros \\
\hline
\end{tabular} & $0,5 \%$ & $13,6 \%$ \\
\hline
\end{tabular}

Em relação ao conhecimento jurídico de deveres e punições para os médicos, em prol do bem maior do paciente e dos direitos dos médicos resguardados pela lei no contexto desta temática, 63,9\% dos estudantes de Medicina e 70,3\% dos de Direito referiram conhecer "leis de proteção ao paciente", e $64,3 \%$ e $54,2 \%$, respectivamente, "leis de proteção ao médico". Esse conhecimento foi obtido principalmente através da faculdade para os dois cursos e em ambas as situações (Tabela 3).

\section{TABela 3}

Conhecimento de "leis de proteção ao paciente" e de "leis de proteção ao médico" e forma de obtenção deste conhecimento pelos estudantes de Medicina e de Direito da UFJF, em maio de 2008

\begin{tabular}{cccccc}
\hline & Medicina & Direito & & Medicina & Direito \\
\hline $\operatorname{Sim}$ & $63,9 \%$ & $70,3 \%$ & $\operatorname{Sim}$ & $64,3 \%$ & $54,2 \%$
\end{tabular}

Obteve na seguinte fonte:

Obteve na seguinte fonte:

\begin{tabular}{lrrlrr} 
Faculdade & $73,0 \%$ & $85,5 \%$ & Faculdade & $76,7 \%$ & $78,1 \%$ \\
TV & $31,3 \%$ & $16,9 \%$ & TV & $12,1 \%$ & $6,3 \%$ \\
Internet & $30,4 \%$ & $16,9 \%$ & Internet & $15,5 \%$ & $12,5 \%$ \\
$\begin{array}{l}\text { Jornal ou } \\
\text { revista }\end{array}$ & $29,6 \%$ & $14,5 \%$ & $\begin{array}{l}\text { Jornal ou } \\
\text { revista }\end{array}$ & $22,4 \%$ & $14,1 \%$ \\
Outros & $9,6 \%$ & $1,2 \%$ & Outros & $12,1 \%$ & $6,3 \%$ \\
Não & $36,1 \%$ & $29,7 \%$ & Não & $35,7 \%$ & $45,8 \%$ \\
\hline
\end{tabular}


A capacidade crítico-reflexiva dos entrevistados explorou a interdisciplinaridade do tema. Tanto os alunos de Medicina quanto os de Direito negaram a aptidão dos profissionais de Medicina para interpretarem erro médico do ponto de vista jurídico (59,8\% na Medicina e 68,6\% no Direito), como também negaram a aptidão dos profissionais de Direito para o interpretarem do ponto de vista técnico (78,5\% na Medicina e $68,6 \%$ no Direito).

Na segunda parte do estudo, quanto à necessidade de abordagem do tema erro médico na graduação, 97,8\% dos estudantes de Medicina e 94,9\% dos de Direito responderam afirmativamente.

Foi questionada ainda a existência de alguma disciplina na graduação que aborde erro médico (Tabela 4). Conseguiram reconhecê-la(s) $61 \%$ na Medicina e $74,6 \%$ no Direito.

\section{TABELA 4}

Existência de alguma disciplina na graduação que aborde erro médico e eficácia da abordagem realizada, na percepção de estudantes de Medicina e de Direito da UFJF, em maio de 2008

\begin{tabular}{lcrc}
\hline $\begin{array}{l}\text { Existe alguma disciplina que aborda } \\
\text { erro médico na sua graduação? }\end{array}$ & Sim & Não & Não sabe \\
\hline Medicina & $61,0 \%$ & $11,3 \%$ & $28,0 \%$ \\
Direito & $74,6 \%$ & $5,1 \%$ & $20,3 \%$ \\
\hline $\begin{array}{l}\text { Para os alunos que responderam } \\
\text { sim quanto à existência dessa(s) }\end{array}$ & & & \\
$\begin{array}{l}\text { disciplina(s), como consideram a } \\
\text { abordagem? }\end{array}$ & Eficaz & & Ineficaz \\
\hline Medicina & $85,8 \%$ & & $14,2 \%$ \\
Direito & $43,3 \%$ & & $56,7 \%$ \\
\hline & & &
\end{tabular}

Na perspectiva dos estudantes de Medicina, as disciplinas reconhecidas como debatedoras do assunto foram Deontologia Médica, Medicina Legal, Bioética, Psicologia Médica, Antropologia, Patologia, Técnica Cirúrgica e outras clínico-cirúrgicas.

Entre os alunos que distinguiram disciplinas que abordam erro médico durante a graduação, foi solicitado que avaliassem, a seu critério, a qualidade dessa abordagem (Tabela 4). No Direito, $56,7 \%$ a consideraram ineficaz, enquanto na Medicina 85,8\% indicaram ser eficaz a abordagem realizada, embora passível de aperfeiçoamento.

A Tabela 5 mostra o sentimento de preparo para lidar com situações que envolvam erro médico no futuro profissional: 27,1\% dos alunos de Medicina não se sentem preparados. Já quanto ao sentimento de preparo para lidar com processos jurídicos que envolvam erro médico no futuro profissional, $37,3 \%$ dos alunos de Direito responderam negativamente.

\section{TABELA 5}

Sentimento de estudantes de Medicina e de Direito da UFJF quanto ao seu preparo para lidar futuramente como profissionais com situações ou processos jurídicos que envolvam erro médico, em maio de 2008

\begin{tabular}{llll}
\hline \multicolumn{3}{c}{ Medicina } & \multicolumn{2}{c}{ Direito } \\
\hline Sim & $27,7 \%$ & Sim & $27,1 \%$ \\
Não & $27,1 \%$ & Não & $37,3 \%$ \\
Não sabe & $45,2 \%$ & Não sabe & $35,6 \%$ \\
\hline
\end{tabular}

\section{DISCUSSÃO}

\section{A percepção do tema erro médico pelos estudantes}

É notória a tendência de judicialização de atos médicos na sociedade nos dias de hoje, tendo-se o erro médico como expoente maior. Isto gera impacto na graduação tanto de Medicina quanto de Direito, uma vez que os alunos trazem uma bagagem de informações sobre o tema e se interessam ainda mais, inclusive já na faculdade, pelas implicações jurídicas de atos médicos, conforme referido pelos entrevistados. Sobretudo entre os acadêmicos de Medicina, já há preocupação em ter que lidar com processos de erro médico no futuro, quando profissionais, refletindo na graduação o conflito desta temática para a classe médica, que, muitas vezes, se vê acuada no exercício da profissão ${ }^{14}$

Além de referirem conhecimento e interesse sobre o tema, os entrevistados demonstraram domínio do mesmo (Tabelas 1 e 2). Os principais fatores desencadeantes do aumento de processos de erro médico percebidos pelos alunos de Direito foram: (a) o aumento do número de faculdades de Medicina, nem sempre aptas a formar profissionais devidamente habilitados para as práticas de saúde $(61,9 \%)^{1,8,15,16}$; (b) a crise do sistema de saúde, com jornadas extensas, má remuneração e escassas condições de trabalho, prejudicando a qualidade do serviço $(52,5 \%)^{17-19}$. Para os alunos de Medicina, foram: (a) a influência da mídia sobre a população ao explorar escândalos e tragédias, alimentando o ciclo vicioso $(55,1 \%)^{14}$; (b) o maior acesso à informação e ao conhecimento dos direitos individuais, com maior reivindicação dos mesmos pelos cidadãos $(54,6 \%)^{20} .54,6 \%$ na Medicina e $43,2 \%$ no Direito citaram ainda a deterioração da relação médico-paciente (RMP) — indispensável à satisfação com os cuidados médicos -, o que resulta no aumento do potencial iatrogênico do médico ${ }^{6,12,16,21}$. Em consonância, fatores apontados como possíveis formas de 
enfrentamento desta questão pelos alunos de Direito foram a melhora da qualidade da formação médica e o incentivo à educação continuada na área (72,9\%). Já para os de Medicina, foi citado o resgate da RMP (79,1\%).

Estabelecer uma boa RMP, pautada em respeito, afeição, transparência, autonomia, compreensão e tolerância, é considerada a melhor maneira de não só prevenir denúncias e processos por erro médico, mas principalmente ofertar uma assistência de saúde mais humana e digna ao paciente ${ }^{12,22}$. Nesse sentido, percebe-se que revigorar e fortalecer a RMP é substancial para a melhoria dos serviços de saúde e a indissociável diminuição de iatrogenias, tendo aqui a educação médica de boa qualidade papel inestimável ${ }^{12,22,23}$.

Mais ainda, 46,7\% na Medicina e 47,5\% no Direito referiram medidas como aliar história clínica, exame físico e tecnologia em benefício do paciente, contrapondo-se ao excessivo tecnicismo atual na saúde ${ }^{15}$. Para $44 \%$ dos entrevistados na Medicina e 51,7\% no Direito, melhorias do sistema de saúde quanto à remuneração dos médicos, ao tamanho da jornada de trabalho e às condições de atendimento ao paciente são válidas para prevenção de erro médico ${ }^{17-19}$.

Procurou-se conhecer também o domínio do tema pelos entrevistados no campo do Direito especificamente, já que há uma ampla gama de leis que tratam de erro médico. Os códigos Civil, Penal, de Defesa do Consumidor e de Ética Médica tanto estabelecem deveres e punições para os médicos, garantindo os direitos do paciente ("leis de proteção ao paciente") 4,9,13,17,20,24, quanto resguardam direitos dos médicos ("leis de proteção ao médico") ${ }^{4,20,24}$. Embora este conhecimento seja de fundamental importância para os graduandos de ambas as áreas, porcentagem superior a 35\% no curso de Medicina referiu não conhecer as implicações legais de atos médicos (Tabela 3).

É também interessante notar que, apesar de o principal meio de obtenção dessas informações pelos estudantes de Medicina ter sido a faculdade, os veículos de comunicação - televisão, internet, jornal ou revista - foram percebidos como agentes que privilegiam a transmissão de "leis de proteção ao paciente" para o grande público, indicando possível unilateralidade, na visão dos acadêmicos de Medicina.

Os alunos de Direito, por sua vez, referiram conhecer mais "leis de proteção ao paciente" (70,3\%) do que "leis de proteção ao médico" (54,2\%), sendo a própria faculdade a principal fonte $(85,5 \%$ e $78,1 \%$, respectivamente). Isto sugere uma tendência à aquisição de maior conhecimento das "leis de proteção ao paciente" do que aquelas referentes ao médico - fator que pode auxiliar na fomentação do ciclo vicioso de erro médico.

$\mathrm{Na}$ interface entre as áreas e para captar o senso crítico-reflexivo dos entrevistados, foi questionada a aptidão de pro- fissionais médicos para interpretar juridicamente situações de erro médico (com noções das leis arroladas), bem como a aptidão de profissionais do Direito para interpretá-las tecnicamente (com noções do conhecimento médico envolvido). As respostas, negativas tanto pela Medicina quanto pelo Direito, ao avaliar essas aptidões mostraram capacidade de fazer uma avaliação crítica no contexto a partir do domínio do tema.

Além disso, essas negativas podem sinalizar que há um déficit, nos médicos, de conhecimento das leis implicadas na regulamentação de sua profissão, além da necessidade de os profissionais do Direito desenvolverem uma visão multidisciplinar ao conduzirem adequadamente um processo judicial, cercando-se de pessoas habilitadas para fazer julgamentos técnicos (por exemplo, perícias médicas).

\section{Percebendo as contribuições da educação médica para o debate ético}

Na segunda parte da pesquisa, procurou-se traçar um panorama de como a discussão do tema erro médico pelas faculdades é percebida sob a ótica dos estudantes entrevistados. Neste trabalho, não nos propomos a fazer uma avaliação efetiva do ensino prestado, já que utilizamos opiniões de estudantes como ponto de partida. Buscamos, sim, entrever, na percepção dos alunos, formas de repensar e aprimorar o papel da educação, sobretudo acerca de sua importância na construção ética dos novos profissionais. Será dada ênfase aqui principalmente à educação médica.

Podem ser desenvolvidas futuras abordagens para avaliar outros temas éticos, bem como o ensino de ética em geral e bioética transversalmente no currículo de Medicina da Universidade Federal de Juiz de Fora, a fim de aprofundar esta discussão acerca do papel da educação médica na formação do ser ético.

Quanto à necessidade de abordar esta temática durante a graduação, 97,8\% dos estudantes de Medicina e 94,9\% dos de Direito a consideraram positiva, o que sugere que se pode investir na graduação, com grande receptividade pelos alunos, como forma de debater temas polêmicos no campo da ética, impactando o "sistema de retroalimentação" de erro médico.

É possível à faculdade de Direito abordar o tema de forma completa, estimulando no aluno o pensamento crítico-reflexivo necessário ao posicionamento ético frente às demandas jurídicas relacionadas a erro médico. Em relação à educação médica, é necessário refletir sobre sua função de informar e fornecer conhecimentos científicos referentes à técnica essencial para o bom exercício da Medicina, como também sobre sua função de aprimorar a consciência social e o senso de responsabilidade do acadêmico. Todos esses fatores são alicerces 
de mais acertos na prática médica e, consequentemente, menos erros e iatrogenias ${ }^{12,23,25}$.

Nesse sentido, a esfera ético-moral do currículo de Medicina é tão importante quanto a esfera teórico-prática, devendo as escolas médicas voltar sua atenção e interesse também para a ética, pois é ela que se encarrega de dotar o profissional de consciência ${ }^{23,25}$. Discutir temas delicados da prática médica e estimular a reflexão acerca de valores éticos da Medicina e de como lidar com estes desafios deve ser uma função curricular, tendo como resultado o estímulo para uma conduta profissional adequada ${ }^{12,23}$.

Para Taquette et al. ${ }^{25}$, porém, existem déficits na formação ético-moral do acadêmico de Medicina, já que disciplinas como Deontologia Médica e Medicina Legal atuam basicamente apresentando o Código de Ética Médica e fazendo a "ponte" entre a Medicina e o Direito, sendo incapazes de desenvolver habilidades para a tomada de decisões autônomas no campo da moral.

Estudantes de Medicina entrevistados afirmaram a necessidade de maior e melhor abordagem da legislação relacionada à profissão e de ética médica em geral, porém de modo diferenciado e com maior praticidade, inclusive para atrair e trazer maior comprometimento dos estudantes. Foram sugeridas aulas voltadas aos direitos e deveres do médico em matérias específicas ou diversificadas, trabalho com casos verídicos/ reais, além de grupos de discussão com situações simuladas e a participação de juristas, advogados e representantes do Conselho Regional de Medicina. Serodio et al. ${ }^{26}$ fizeram um belo trabalho de pesquisa nesta mesma linha de raciocínio, sugerindo nova metodologia de ensino-aprendizagem com base em estudo de casos para questões éticas.

É necessário inserir modelos de aprendizado que reflitam mais a prática e preparem melhor os estudantes para a realidade profissional e as necessidades emergentes da sociedade, estimulando em cada um deles a consolidação de princípios éticos e humanistas ${ }^{27-29}$.

Quanto à percepção de disciplinas na graduação que abordam erro médico (Tabela 4), encontrou-se uma dicotomia entre os grupos, tendo maior facilidade para reconhecê-las os estudantes de Direito $(74,6 \%)$, que avaliaram a abordagem como ineficaz $(56,7 \%)$, enquanto na Medicina foi considerada eficaz $(85,8 \%)$ por aqueles que as reconheceram $(61,0 \%)$. Isto pode refletir maior maturidade dos alunos de Direito e melhor discernimento sobre a dinâmica de seu curso, além do fato de este ser possivelmente um grupo mais crítico com relação à qualidade do ensino vivenciado.

O perfil dos estudantes de Medicina foi indagado pelos próprios alunos deste curso, numa autorreflexão em que cita- ram a "mentalidade" do acadêmico de Medicina como obstáculo ao bom desenvolvimento das aulas. Foi argumentada a necessidade de todos os colegas compartilharem maior interesse pela educação médica e pela Medicina em si - para também terem maior comprometimento com a profissão quando médicos. Importante papel da educação médica é aprimorar a personalidade dos alunos durante o processo de formação dos futuros médicos, uma vez que esta é uma primeira etapa para o desenvolvimento de habilidades éticas no campo das ações autônomas ${ }^{12}$.

Procurou-se delinear a percepção dos estudantes quanto ao seu preparo para se posicionar de maneira ética e autônoma em situações futuras de questionamento e desafio ético-moral. $\mathrm{Na}$ Tabela 5, as denominadas "situações de erro médico na vida profissional" são situações eticamente conflituosas, que exigem do profissional atitudes pautadas nos valores éticos da medicina e, em última instância, de sua própria consciência.

Referido pelos estudantes de Medicina - com paralelo no Direito -, o sentimento de despreparo para lidar com "situações de erro médico na vida profissional" pode demonstrar um imperativo de aprimoramento de pilares essenciais da educação médica, como o eixo humanístico ${ }^{27}$. Alunos entrevistados, inclusive, avaliaram que sua formação deve se pautar primordialmente nas bases holísticas da medicina e no efetivo resgate da humanização como forma de se aperfeiçoarem para a prática médica - o que estreita a possibilidade de ocorrência de ações iatrogênicas. Algumas disciplinas desse eixo, como Psicologia Médica e Antropologia, foram também citadas como debatedoras do tema erro médico na graduação.

Portanto, devem ser bem trabalhados assuntos como a relação médico-paciente (RMP), a comunicação entre médicos, pacientes e seus familiares, o enfoque biopsicossocial do paciente, visto principalmente como ser humano e tratado com base em atributos médicos como intuição, empatia, humildade, comunicabilidade e resiliência, em disciplinas como Psicologia Médica, Semiologia e Introdução à Prática Médica, entre outras $^{12,22,24,27}$.

A educação médica pode contribuir substancialmente para a formação de profissionais mais bem informados e qualificados, desenvolvendo nos acadêmicos as bases para uma conduta médica adequada - competências e habilidades técnicas, mas também, e tão importantes quanto, valores éticos e morais. Desta forma, se molda o estudante de Medicina com visão humana aprimorada e responsável pessoal e profissionalmente, com plena consciência de seu compromisso social, extremamente importantes para o bom exercício da arte médica ${ }^{27}$ 


\section{CONCLUSÃO}

A atualidade do tema erro médico traz para as graduações de Medicina e de Direito o debate ético. É factível e necessário reconhecer a importância desse tipo de reflexão durante a formação profissional, sobretudo devido ao interesse dos estudantes em adquirir mais conhecimentos acerca desse tópico.

Neste contexto, tanto a educação médica quanto a educação em Direito podem ter papel diferenciado ao incentivarem a discussão sobre o tema, contribuindo para o enfrentamento racional da questão ao fomentarem uma formação em Direito mais crítico-reflexiva, com melhor discernimento das pendências jurídicas, e uma formação em Medicina mais ética e holística, com menor propensão a erros e iatrogenias.

\section{AGRADECIMENTOS}

A Áureo Augusto de Almeida Delgado e Cristiana Silva de Mello, pelas sugestões, comentários e revisão para fins de publicação do original.

\section{REFERÊNCIAS}

1. Vásquez EM. Ética, calidad, competencia médica [Editorial]. Rev Colomb Cir [periódico na internet]. 2001 [acesso em 15 mar. 2008];16(4):193-6. Disponível em: http:/ /www. encolombia.com/medicina/cirugia/ciru16401editorial.htm

2. Franco A. Iatrogenia en cirugía ¿Cómo evitarla? Rev Colomb Cir [periódico na internet]. 2006 [acesso em 15 mar. 2008];21(1):15-22. Disponível em: http://encolombia. com/medicina/cirugia/Ciru21106-Iatrogenia.htm

3. Vieira S, Hossne WS. Experimentação com seres humanos. Ciênc Ensino [periódico na internet].1997 [acesso em 15 mar. 2008];(2):7-9. Disponível em: http://www.fisica.ufc. br/conviteafisica/cien_ens_arquivos/numero2/p07.pdf

4. Rencoret GS. Auditoria medica: demandas y responsabilidad por negligencias medicas. Gestion de calidad: riesgos y conflictos. Rev Chil Radiol [periódico na internet]. 2003 [acesso em 22 mar. 2008];9(3):157-60. Disponível em: http:/ / www.scielo.cl/scielo.php?script=sci_arttext\&pid=S0717-93082003000300008\&lng=es\&nrm=iso\&tlng=es

5. Rosselot EJ. Errores en Medicina. Rev Med Chile [periódico na internet].2001 [acesso em 15 mar. 2008];129(12):1455-8. Disponível em: http://www. scielo.cl/scielo.php?script $=$ sci_arttext\&pid=S0034$-98872001001200013 \& \operatorname{lng}=p t$

6. Sutil LP. Manejo de los errores en medicina. Rev Med Chile [periódico na internet]. 2001 [acesso em 15 mar. 2008];129(12):1470-2. Disponível em: http://www. scielo.cl/scielo.php?script $=$ sci_arttext\&pid=S0034$-98872001001200017 \& \operatorname{lng}=p t$
7. Carvalho M, Vieira AA. Erro médico em pacientes hospitalizados. J Pediatr (Rio J) [periódico na internet]. 2002 [acesso em 22 mar. 2008];78(4):261-8. Disponível em: http:/ / www.scielo.br/scielo.php?script=sci_arttext\&pid=S00217 $5572002000400004 \& \operatorname{lng}=e n \& n r m=i s o \& t \operatorname{lng}=p t$

8. Reason J. Human error: Models and management. BMJ. 2000;(320):768-70.

9. Carvallo A. Consideraciones éticas sobre el error en medicina. Rev Med Chile [periódico na internet]. 2001 [acesso em 15 mar. 2008];129(12):1463-5. Disponível em: http:/ / www.scielo.cl/scielo.php?script=sci_arttext\&pid=S0034$-98872001001200015 \& \operatorname{lng}=\mathrm{pt}$

10. Franco A. La seguridad clínica de los pacientes: entendiendo el problema. Colomb Med [periódico na internet]. 2005 [acesso em 15 mar. 2008];36(2):130-6. Disponível em: http:/ / colombiamedica.univalle.edu.co/Vol36No2/cm36n2a10.pdf

11. Goic A. Fuentes de error en clínica. Rev Med Chile [periódico na internet]. 2001 [acesso em 15 mar. 2008];129(12):1459-62. Disponível em: http://www. scielo.cl/scielo.php?script=sci_arttext\&pid =S0034$-98872001001200014 \& \operatorname{lng}=$ pt\&nrm $=$ iso

12. Tavares FM. Reflexões acerca da iatrogenia e educação médica. Rev Bras Educ Med [periódico na internet]. 2007 [acesso em 22 mar. 2008];31(2):180-5. Disponível em: http:/ /www.scielo.br/pdf/rbem/v31n2/09.pdf

13. Udelsmann A. Responsabilidade civil, penal e ética dos médicos. Rev Assoc Med Bras. 2002; 48(2):172-82.

14. Carvalho Fortes PA. Aspectos ético-jurídicos da responsabilidade civil do médico em prática liberal. Rev Saúde Pública. 1990;24(6):518-22.

15. Mendes W, Travassos C, Martins M, Noronha JC. Revisão dos estudos de avaliação da ocorrência de eventos adversos em hospitais. Rev Bras Epidemiol. 2005;8(4):393-406.

16. Chaves A. Responsabilidade civil do ato médico: ato médico: Contrato de meios. Rev Jurídica. 1995;207(19).

17. Souza NTC. Erro médico: conceitos jurídicos. Rev Âmbito Jurídico [periódico na internet]. 2006 [acesso em 22 mar. 2008];9(32):[cerca de 2p.]. Disponível em: http://www. ambito-juridico.com.br/pdfsGerados/artigos/3258.pdf

18. Souza MMR. A responsabilidade civil do médico. Jus Navigandi [periódico na internet]. 2000 [acesso em 4 abr. 2008];5(46):[cerca de 1 p.]. Disponível em: http:/ /jus.uol.com. $\mathrm{br} /$ revista/texto/1868/a-responsabilidade-civil-do-medico

19. Souza NTC. Erro médico: uma visão. Jus Navigandi [periódico na internet]. [acesso em 4 abr. 2008]. Disponível em: http:/ / www.bureaujuridico.com.br/medicina/artigos / art_bm006.htm 
20. Porras JS. El Seguro contra la responsabilidad civil del médico. Med Leg Costa Rica [periódico na internet].1999 [acesso em 15 mar. 2008];16(1-2). Disponível em: http://www. scielo.sa.cr/scielo.php?script=sci_arttext\&pid=S1409$-00151999000200006 \& \operatorname{lng}=$ pt\&nrm=iso\&tlng=es

21. Aguiar Júnior RR. Responsabilidade civil do médico. Rev Jurídica. 1997;(231):121-2.

22. Gomes JCM. O atual ensino da ética para os profissionais de saúde e seus reflexos no cotidiano do povo brasileiro. Bioética [periódico na internet].1996 [acesso em 4 abr. 2008];4(1). Disponível em: http://www.portalmedico.org. $\mathrm{br} / \mathrm{revista} /$ ind1v4.htm

23. Zampieri Júnior S, Zampieri AM. Erro médico: semiologia e implicações legais. Jus Navigandi [periódico na internet].1998 [acesso em 4 abr. 2008];(26). Disponível em: http:/ /jus2.uol.com.br/doutrina/texto.asp?id=1866

24. Bitencourt AGV, Neves NMBC, Neves FBCS, Brasil ISPS, Santos LSC. Análise do erro médico em processos ético-profissionais: implicações na educação médica. Rev Bras Educ Med [periódico na internet]. 2007[acesso em 11 abr. 2008];31(3):223-8. Disponível em: http://www.scielo.br/ pdf/rbem/v31n3/04.pdf

25. Taquette SR, Rego S, Schramm FR, Soares LL, Carvalho SV. Situações eticamente conflituosas vivenciadas por estudantes de medicina. Rev Assoc Med Bras [periódico na internet].2005 [acesso em 11 abr. 2008];51(1):23-8. Disponível em: http://www.scielo.br/pdf/ramb/v51n1/a15v51n1.pdf

26. Serodio AMB, Almeida JAM. Situações de conflitos éticos relevantes para a discussão com estudantes de Medicina: uma visão docente. Rev Bras Educ Med [periódico na internet]. 2009 [acesso em 12 jun. 2009];33(1):55-62. Disponível em: http:/ /www.scielo.br/pdf/rbem/v33n1/08.pdf

27. Rego S, Gomes AP, Siqueira-Batista R. Bioética e Humanização como Temas Transversais na Educação Médica. Rev
Bras Educ Med [periódico na internet]. 2008 [acesso em 12 jul. 2009];32(4):482-91. Disponível em: http:/ /www.scielo. $\mathrm{br} / \mathrm{pdf} / \mathrm{rbem} / \mathrm{v} 32 \mathrm{n} 4 / \mathrm{v} 32 \mathrm{n} 4 \mathrm{a} 11 . \mathrm{pdf}$

28. Dantas F, Sousa EG. Ensino da Deontologia, Ética Médica e Bioética nas Escolas Médicas Brasileiras: uma Revisão Sistemática. Rev Bras Educ Med [periódico na internet]. 2008 [acesso em 12 jul. 2009];32(4):507-17. Disponível em: http://www.scielo.br/pdf/rbem/v32n4/v32n4a14.pdf

29. Munõz DR. O Ensino da Bioética nas Escolas Médicas. In: Pessini L, Barchifontaine CP, org. Bioética e Longevidade Humana. São Paulo: Centro Universitário São Camilo: Loyola; 2006. p. 217-35.

\section{CONTRIBUIÇÃO DOS AUTORES}

José Antônio Cheuen Neto e Mauro Toledo Sirimarco: orientadores do projeto de pesquisa. Nathália Stela Visoná de Figueiredo: autora do projeto de pesquisa, colaborou na redação, coleta de dados e confecção da seção de resultados. Tatiane Neto Barbosa: autora do projeto de pesquisa, colaborou na coleta de dados e confecção da seção de resultados. thiago Gonçalves da Silveira: colaborou na confecção da seção de resultados.

\section{CONFLITO DE INTERESSES}

Declarou não haver.

\section{ENDEREÇO PARA CORRESPONDÊNCIA}

José Antônio Chehuen Neto

Av. Independência, 1495 — apto 1001

Centro - Juiz de Fora

CEP 36016-320 - MG

E-mail: chehuen.neto@yahoo.com.br 